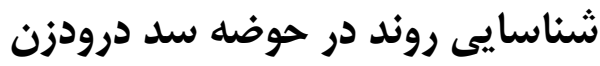

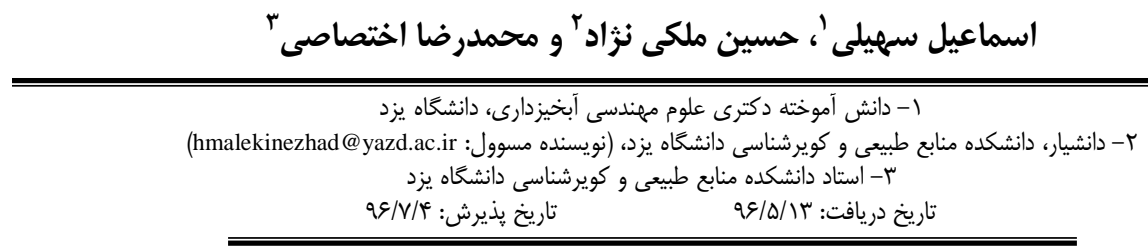

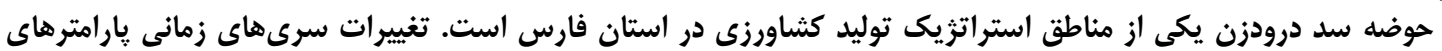

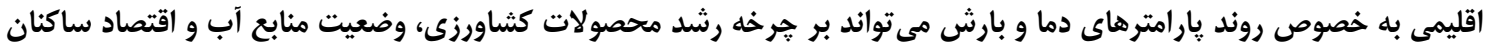

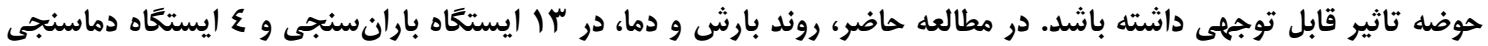

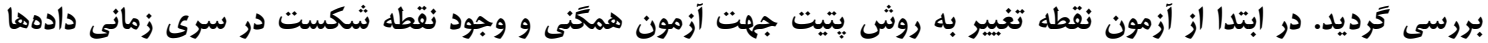

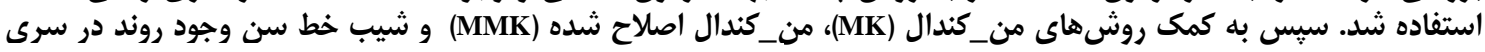

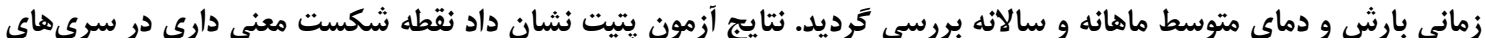

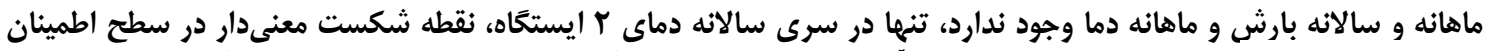

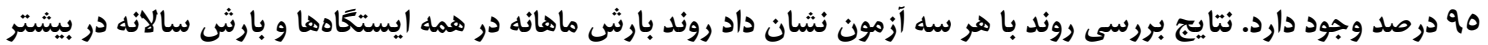

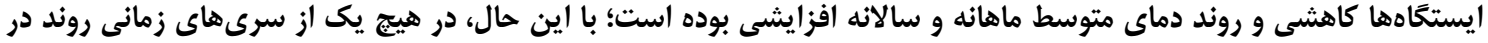

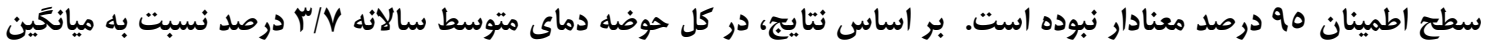

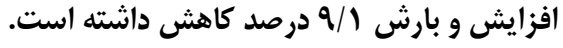

وازههاى كليدى: آزمون روند، استان فارس، شيب سن، من كندال اصلاح شده، نقطه تغيير

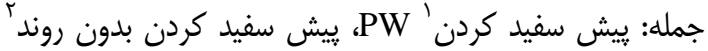
TFPW

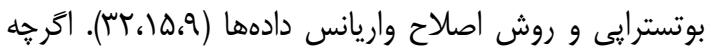

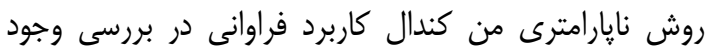

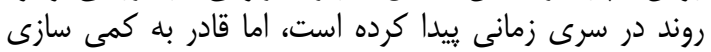

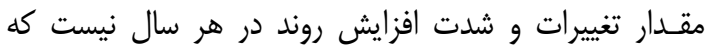

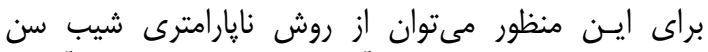

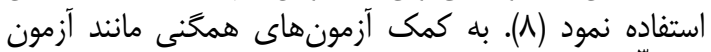

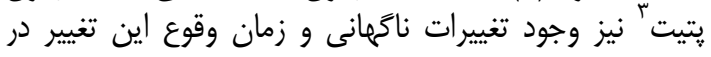

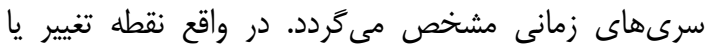

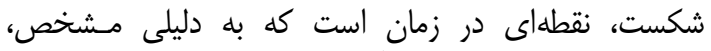
يارامترهاى سرى زمانى در آن نقطه دستخوش تغان آنيير گرديده

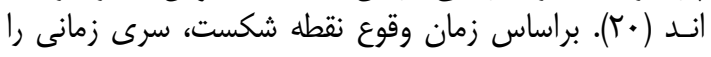

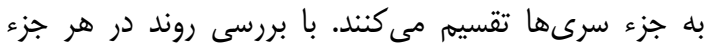

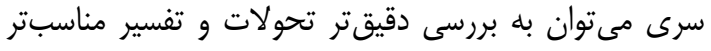

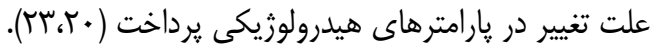

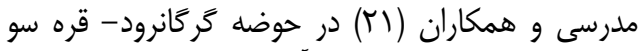

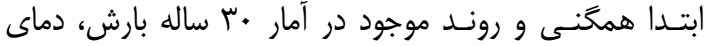

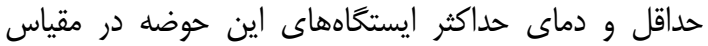

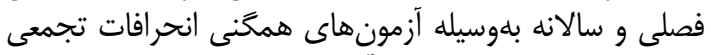

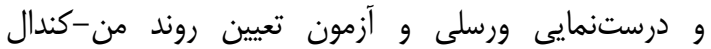

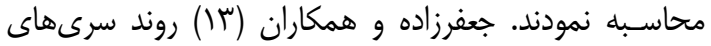

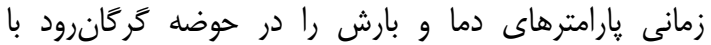

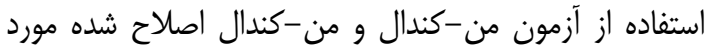

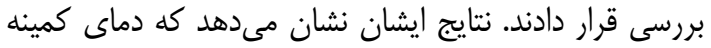

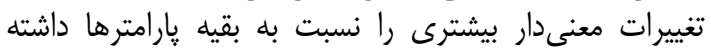

\section{مقدمه}

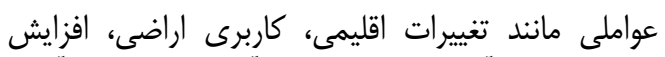

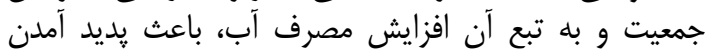

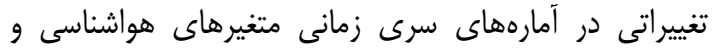

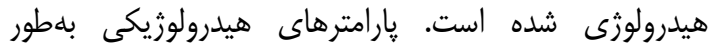

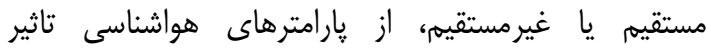

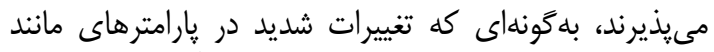

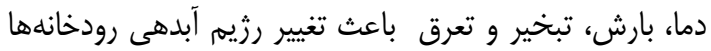

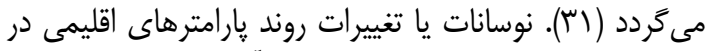

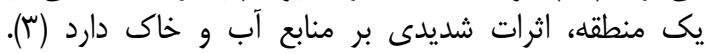

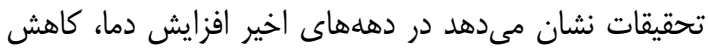

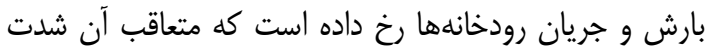

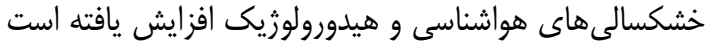

.(19619.V)

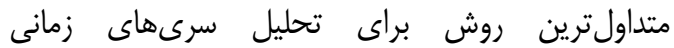

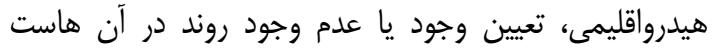

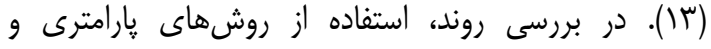

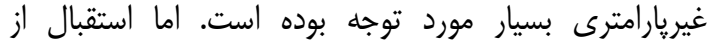
روشهاى غيريارامترى و بلهخصوص من اكندال بيشتر بوده

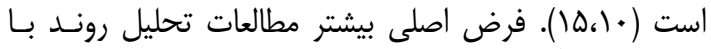

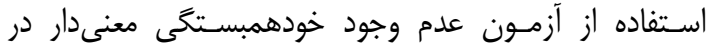

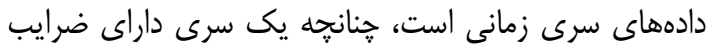

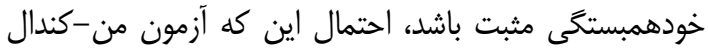

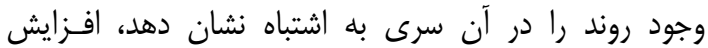

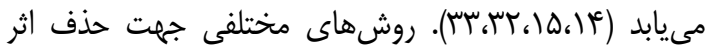

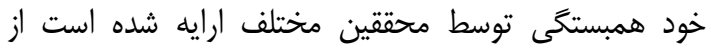


كل سرى دادهاى سالانه شناسايى نشد، ولى آناليز جزء إئاء

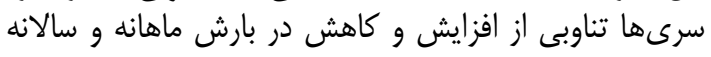
را نشان داد. حوضه سد درودزن يكى از مناطق استراتزيك توليد

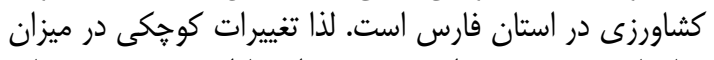

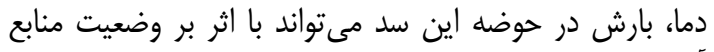

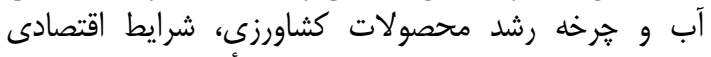

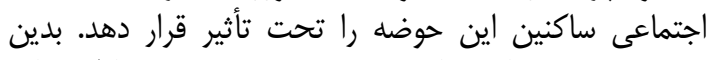

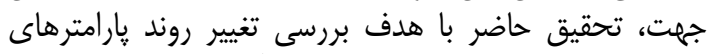

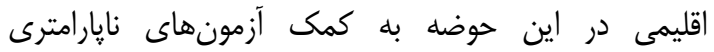
شناسايى روند انجام شد.

\section{مواد و روشها مورد مطالعه منطقه مورد مطالعه}

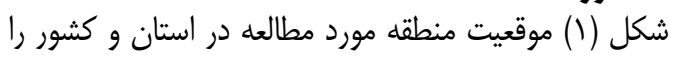

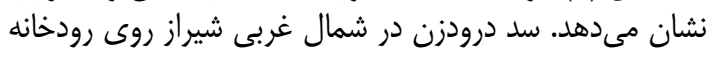

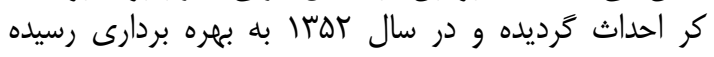

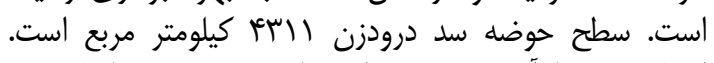

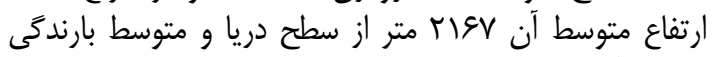

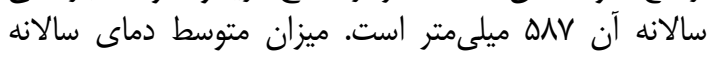

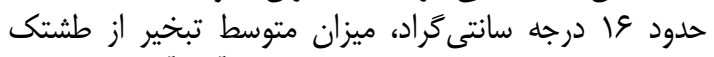

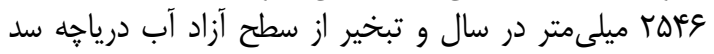

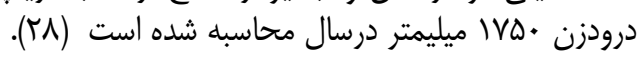

است و بارش نيز داراى شيب روند مثبت بوده است. حجام و

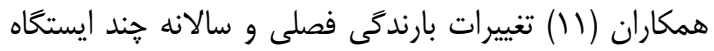

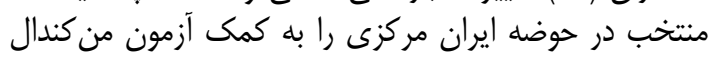

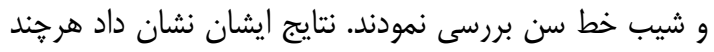

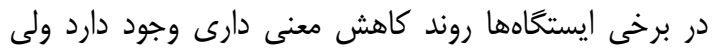

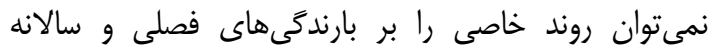

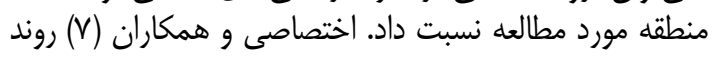

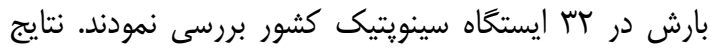

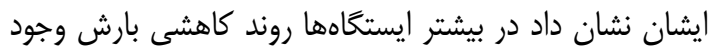

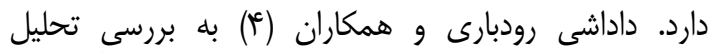

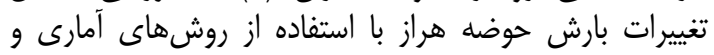

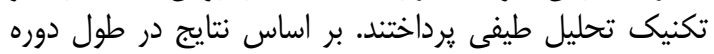

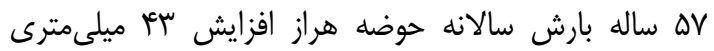

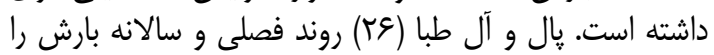

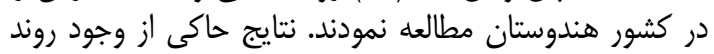

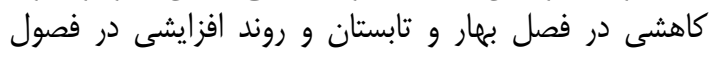

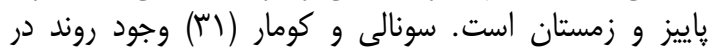

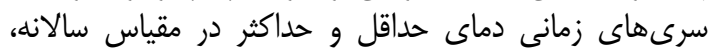

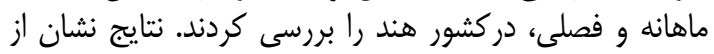

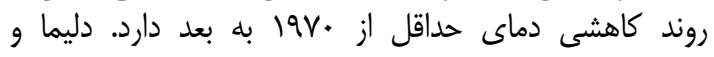

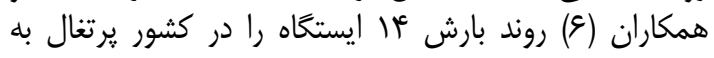

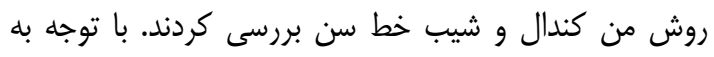

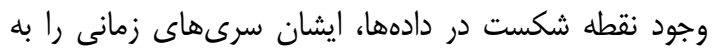

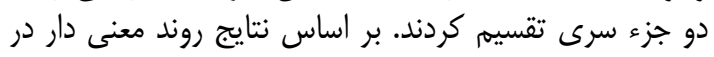

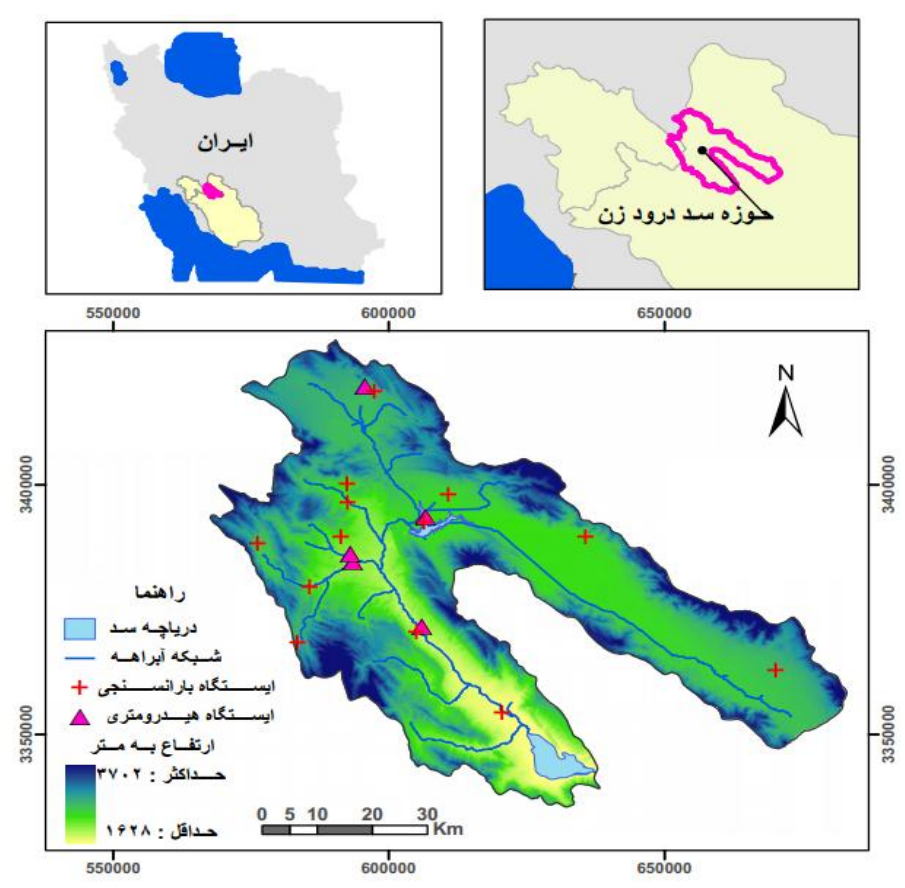

شكل 1- موقعيت منطقه مورد مطالعه

Figure 1. Location of study area 
آمارى IV تا هi ماله در محدوده حوضه سد درودزن استفاده

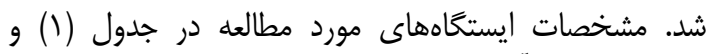
يراكنش مكانى آنها در شكل (1) نشان داده شده است.
دادههاى مورد استفاده

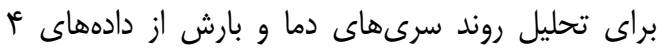

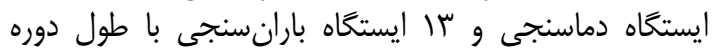

جدول ا- مشخصات ايستخاههاى باران سنجى،آب سنجى و دما Table 1. Properties of Rain Gauge, hydrometer and temperature stations

\begin{tabular}{|c|c|c|c|c|c|}
\hline ميانكين بارش به /mm/ دما به & طول دوره آمارى سال & عرض جغرافيايى & طول جغرافيايى & نوع ايستخاه & 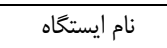 \\
\hline $\operatorname{saq} / 9$ & tr & $r \cdot / \mu$ & $\Delta T / \Delta \Lambda$ & باران سنجى & سد درودزن \\
\hline $1.91 / 1$ & iv & $r \cdot / \mu^{a c}$ & $\Delta \backslash / M$ & باران سنجى & كمهر \\
\hline$r V N / \mu$ & re & $r \cdot / q$. & $\Delta T / \cdot T$ & باران سنجى & خسروشيرين \\
\hline $019 / 1$ & re & $r \cdot / 9 r^{c}$ & Q)/१ఎ & باران سنجى & جمال بيخ شيرين \\
\hline $\mathrm{FHT} / \mathrm{T}$ & سب & $r \cdot / \mu r$ & $\Delta T / \Delta Q$ & باران سنجى & امام زاده اسماعيل \\
\hline GMA & M & $r \cdot / r^{\mu}$ & D)/9V & باران سنجى & 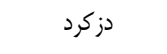 \\
\hline IEN/G & rq & $r \cdot 199$ & $\Delta T / 11$ & باران سنجى & دهكده سفيد \\
\hline$\Delta \cdot 1 / v$ & ru & $r \cdot / r q$ & $\Delta T / F V$ & باران سنجى & 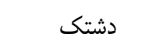 \\
\hline$\Delta e \cdot / r$ & rq & $r \cdot / \Delta \Delta$ & $\Delta) / 19$ & باران سنجى & جوبخله \\
\hline$\Gamma \mu / \mu$ & re & $r . / 4 q$ & $\Delta T / V V$ & باران سنجى & احمد آباد \\
\hline$F \Delta / / 1$ & fer & $r \cdot / \mu r$ & $\Delta T / T \Delta$ & باران سنجى & عباس آباد \\
\hline$r q q / \varphi$ & 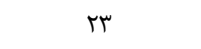 & $r \cdot / v$ & $\Delta T / \backslash G$ & باران سنجى & سده \\
\hline $\mathrm{ev} / 1$ & $i \Delta$ & $r \cdot / 4 \Delta$ & $\Delta 1 / 1$. & باران سنجى & جمريز \\
\hline 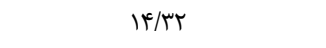 & ז4 & $r \cdot / \% \Delta$ & $\Delta 1 / 1$. & دما سنجى & جمريز \\
\hline $11 / \pi r$ & זו & $r \cdot / \mu^{c}$ & $\Delta I / M$ & دما سنجى & كمهر \\
\hline $10 / r$ & ז4 & rq/q & $\Delta T / V$. & دما سنجى & مهر آباد \\
\hline $1 \% / 9$ & r & $r \cdot / v$ & $\Delta T / \backslash Q$ & دما سنجى & سده \\
\hline
\end{tabular}

كندال بر روى جز سرىها اعمال گرديد. همجنين در دور صورت معنادار بودن نقطه شكست در سرى سرى دادهها، درصد تغييرات

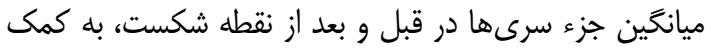

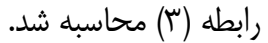

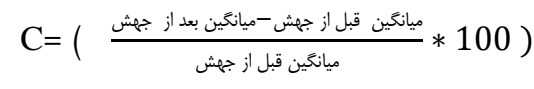

كه در اين رابطه Cسبت تغييرات دو جزء سرى به درصد

$$
\text { آزمون من كندال }
$$

فرض صفر اين آزمون بر تصادفى بودن و عدمال عدم وجود روند

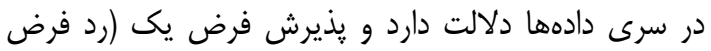

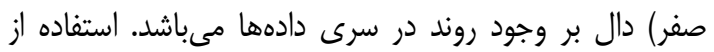

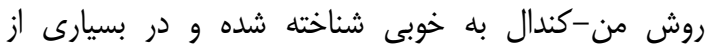

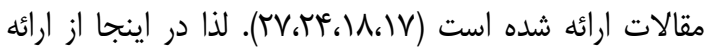

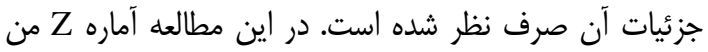

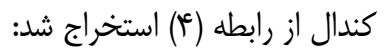

$$
Z=\left\{\begin{array}{ll}
\frac{s-1}{\sqrt{\operatorname{Var}(s)}} & \xi s>0 \\
0 & \xi \leq=0 \\
\frac{s+1}{\sqrt{\operatorname{Var}(s)}} & \xi \leq<0
\end{array}\right\}
$$

\section{آزمون همًَنى و نقطه تغيير يتيت}

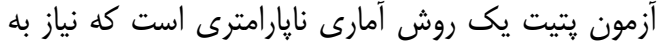

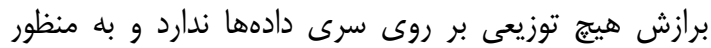

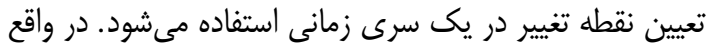

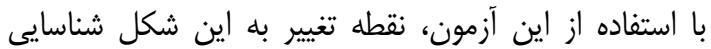

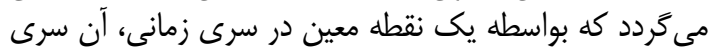

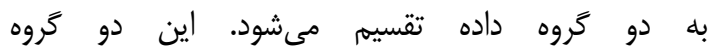

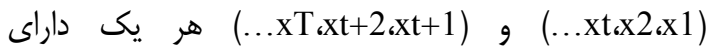

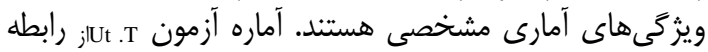
(1) (1) بلدست آمد: آمدا:

$\mathrm{U}_{\mathrm{t} \mathrm{T}}=\sum_{i=1}^{t} \sum_{j=t+1}^{T} D_{i j}$

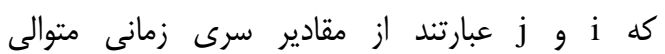
(x1

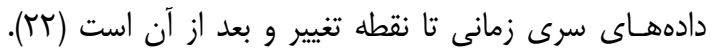

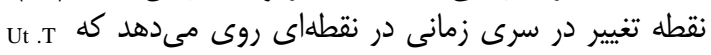

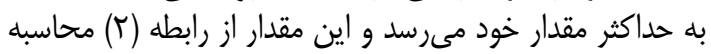

$$
U_{t, T}=\underset{1 \leq t<T}{\operatorname{Max}}\left|U_{t, T}\right|
$$

براى آزمون معنى دارى آمارى نقطه تغيير مقدار محاسبه

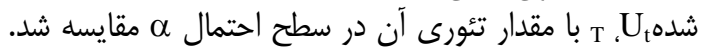

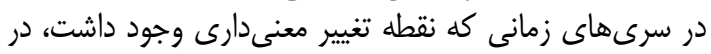

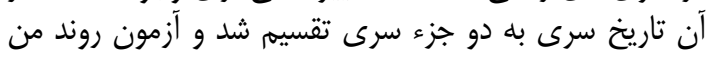


اسـاس محاسبه شيب تغييرات بين كليه جفت دادهاد إداى

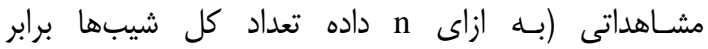

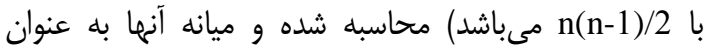

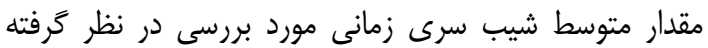

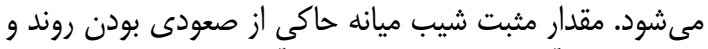

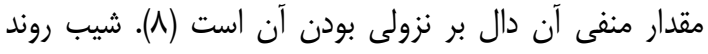

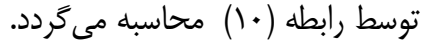

$\beta=\operatorname{Median}\left(\frac{X_{j}-X_{t}}{j-t}\right)$

$\forall t<j \quad$ ، $t=1$ ، 2 ،3 $\ldots \ldots \ldots n$

درصد تغييرات بارش و دما نسبت به ميانكَين

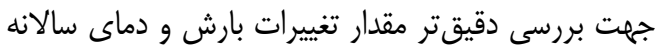

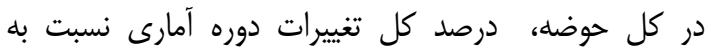

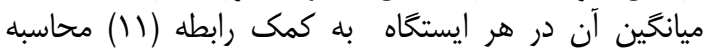

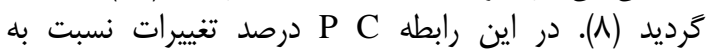
ميانكين، N N معداد سال آمارى، آمارى و SS شيب خط سن مربوط به هارامتر است ميانين

$$
P C=\frac{(S S \times N)}{\bar{X}}
$$

\section{نتايج و بَحث آزمون همخَنى و نقطه تغيير يتيت}

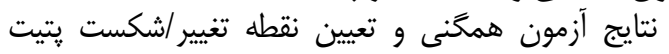

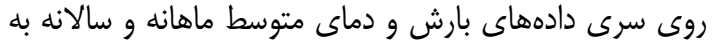

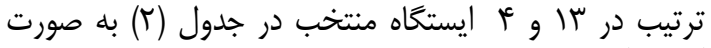

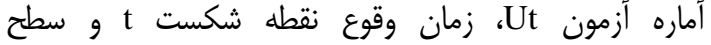

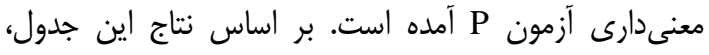

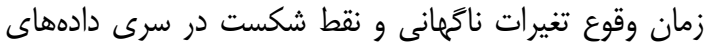

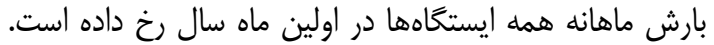

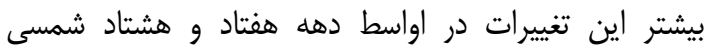

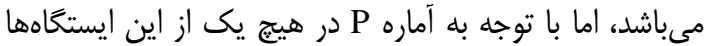

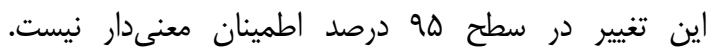
همجنين در سرى دادههاى بارش سالانه نيز نقاط شكست

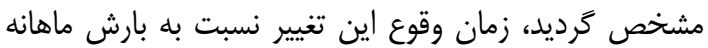

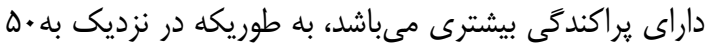

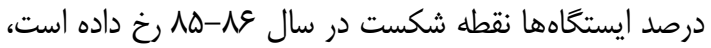

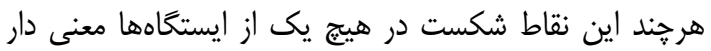

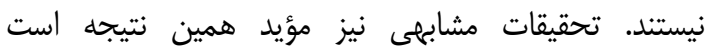

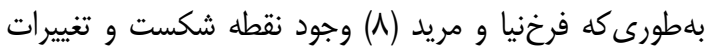

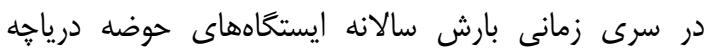

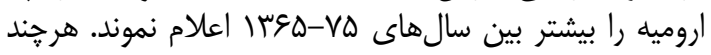

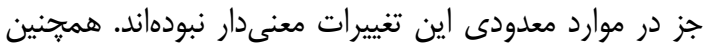

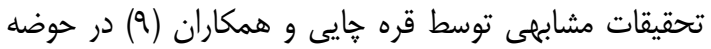

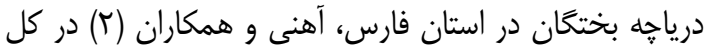

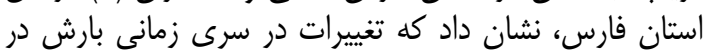

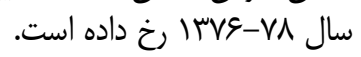

با فرض دو دامنه آزمون روند، فرضيه صفر در صورتى يذيرفته $|Z|<Z_{\alpha / 2}$

كه $\alpha$ سطح معنىدارى است كه براى آزمون در نظر

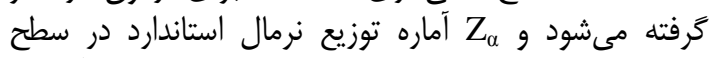

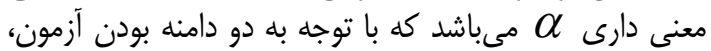

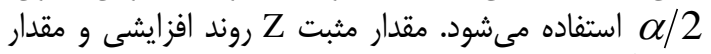

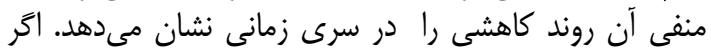

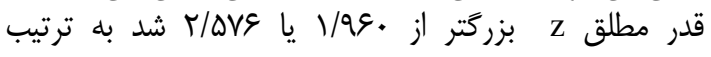

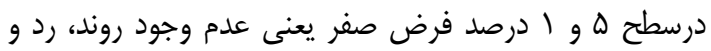

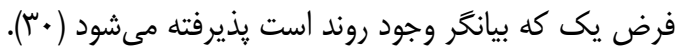
آزمون من -كندال اصلاح شده يلان

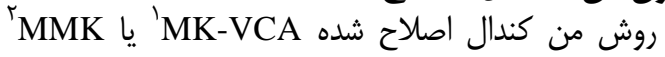

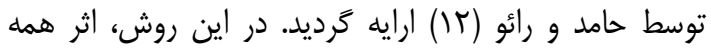

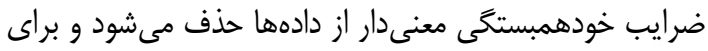

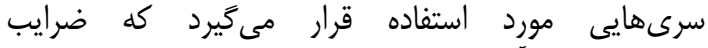

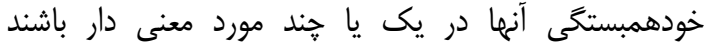

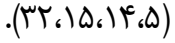

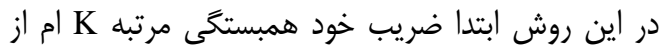

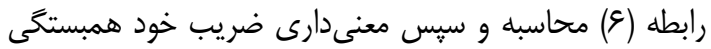

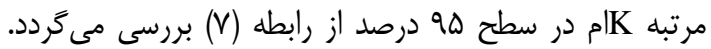

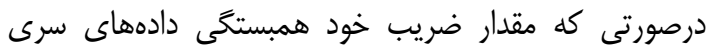

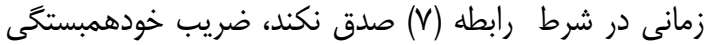
معنى دار بوده و بايد اثر آن حذف تر درد.

$$
r k=\frac{\frac{1}{n-k} \sum_{t=1}^{n-k}\left(x_{t}-\bar{x}_{t}\right)\left(x_{t+k}-\bar{x}_{t}\right)}{\frac{1}{n} \sum_{t=1}^{n}\left(x_{t}-\bar{x}_{t}\right)^{2}}
$$

$$
\frac{1-1.96 \sqrt{n-k-1}}{n-k} \leq r k \leq \frac{1+1.96 \sqrt{n-k-1}}{n-k}
$$

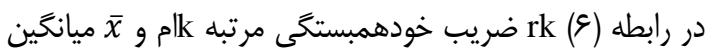

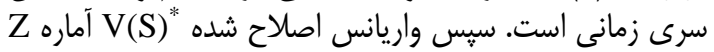
من كندال از روابط (^) و (9) محاسبه كَرديد.

$$
V(S)^{*}=V(S) \frac{n}{n^{*}}
$$

$\frac{n}{n^{*}}=1+\frac{2}{n(n-1)(n-2)} \sum_{k=1}^{n-1}(n-k)(n-k-$
1) $(n-k-2)$

در رابطه (^) و (9)، V(S) واريانس دادهها درروش من كندال

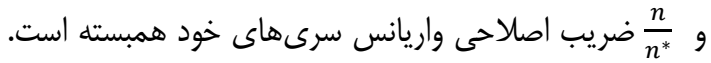
در نهايت آماره Z آزمون من كندال با جاريان جايكزينى واريانس

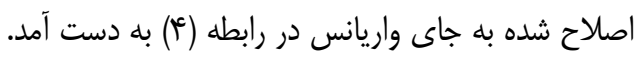
روش تخمينكَ شيب سن (تايل-سن)

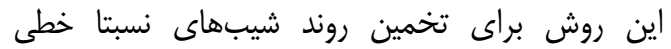

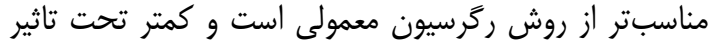

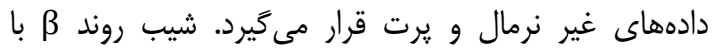

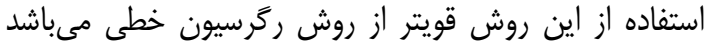

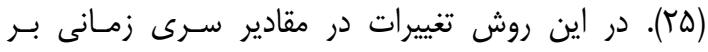


دادها و و عدم همكنى آنها مىباشد. بنابراين سرى زمانى

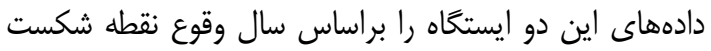

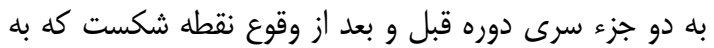

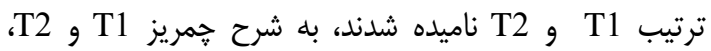

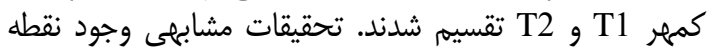

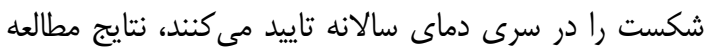

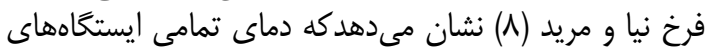

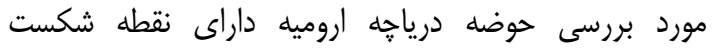

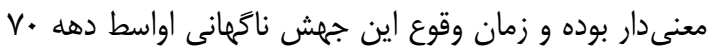

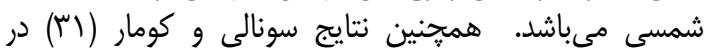
كشور هندوستان نشان داد كه از •19V به به بعد تغييرات دمايى راح داده است.
نتايج آزمون همحنى يتيت در جدول (r) نشان آمده است.

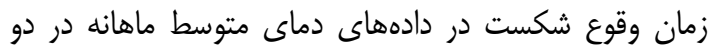

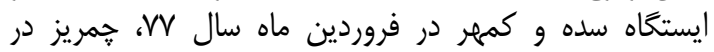

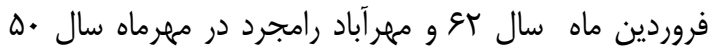

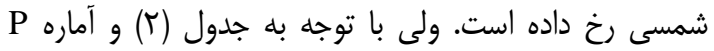

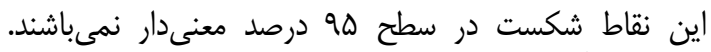

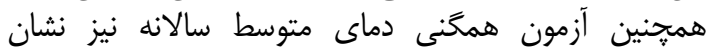

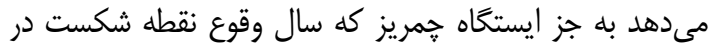

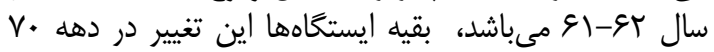

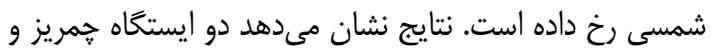

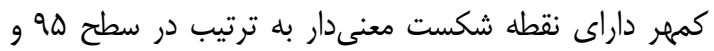

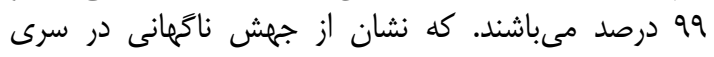

جدول r- نتايج آزمون همخنى يتيت بر سرى دادهاى بارش و دماى متوسط ماهانه و سالانه Table 2. The results of Pettitt homogeneity test on monthly and annual mean rainfall and temperature data series

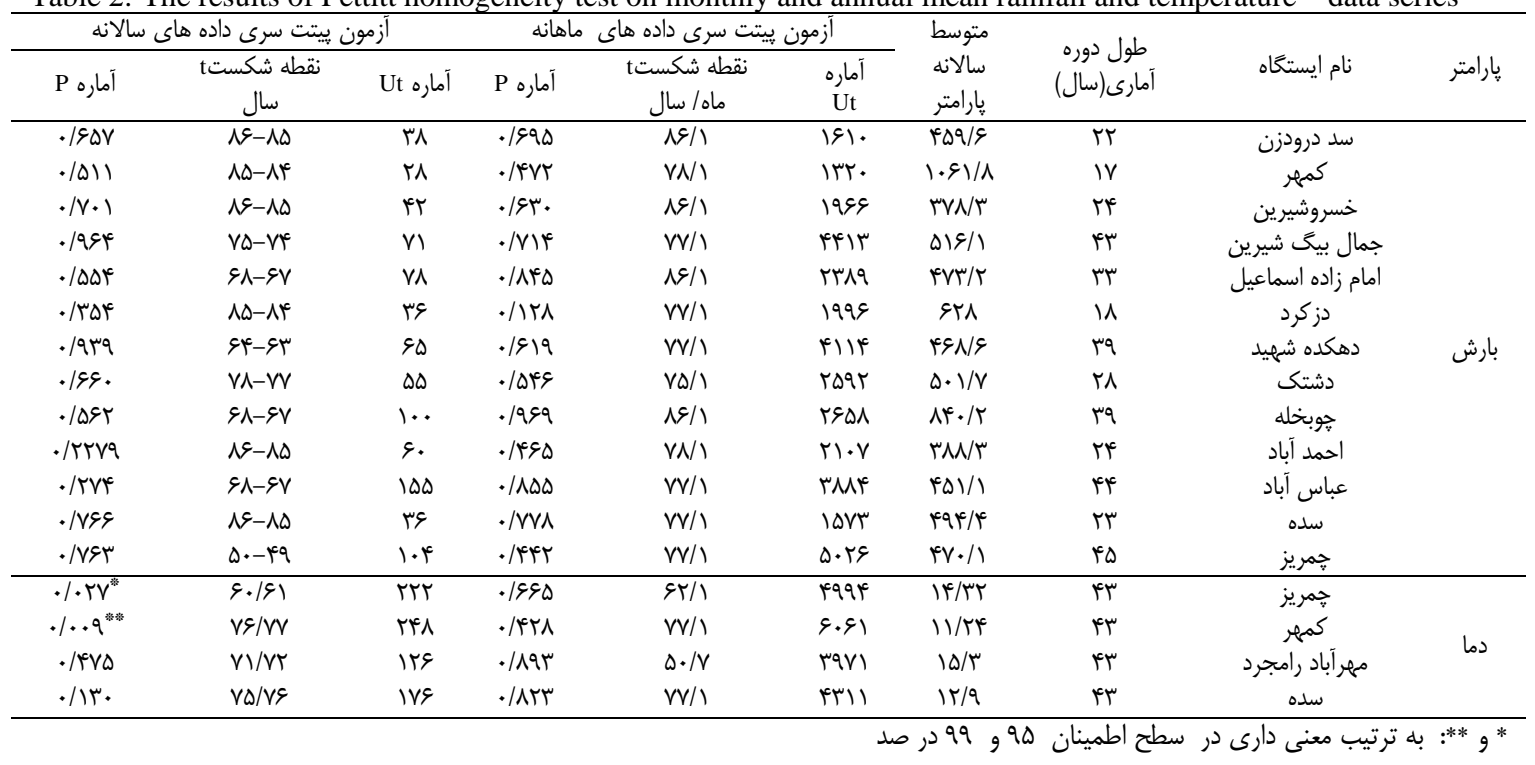

ولى اين روندهاى نزولى معنى دار نمىباشند. نتايج آزمون روند

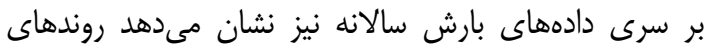

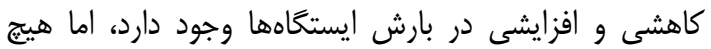

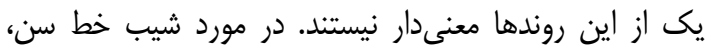

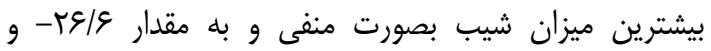
إسن ب -11/9V

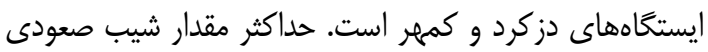

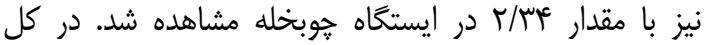
مقادير شيب سن در اغلب ايستخاهها منفى است.
نتايج آزمون روند (من-كندال و من-كندال اصلاح شده) بيس از بررسى همكنى دادهها و نتايج استفاده از آزمون

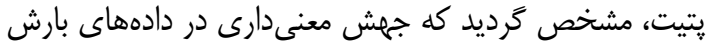

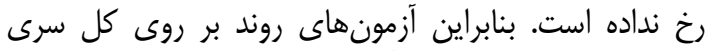

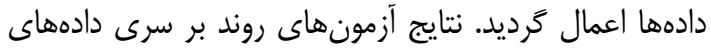

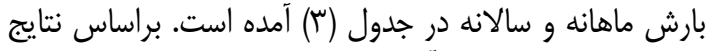

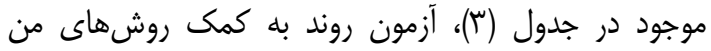

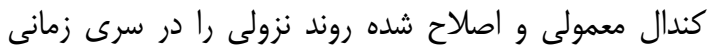

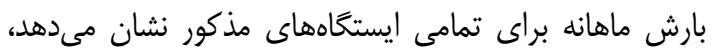


Table 3. Results of rainfall trend test in the 13 mentioned stations

جدول س- نتايج آزمونهاى روند بارش در سا ايستخاه مورد مطالعه

\begin{tabular}{|c|c|c|c|c|c|c|c|c|c|}
\hline \multicolumn{4}{|c|}{ بارش ماهانه } & \multicolumn{5}{|c|}{ بارش سالانه } & \multirow[b]{2}{*}{ ايستخاه } \\
\hline MMK & MK & $\begin{array}{c}\text { Kendall's } \\
\text { tau }\end{array}$ & آماره S & Sen Slope & MMK & MK & $\begin{array}{c}\text { Kendall's } \\
\text { tau }\end{array}$ & آماره S & \\
\hline.$- / 998$ & -./ATY & (-./. & -1114 & $-r / \lambda \mu$ & $-\cdot / \Delta Q T$ &.$- /$ DQr & $-.1 .9 \Delta$ & $-t+$ & سد درودزن \\
\hline.$- / 849$ & $-\cdot / 4 \mid 9$ &.$- .1 \cdot 1 \mathrm{~V}$ & -99 . & $1 / \cdot 1$ &.$/ 191$ &.$/ 191$ & سז.|• & 9 & خسروشيرين \\
\hline$-\cdot / V Y q$ &.$- / 09 \mathrm{~V}$ &.- .1 .19 & שחצr- & • & • & - & • & . & جمال بيگ شيرين \\
\hline$-\cdot / \pi V V$ & שוT/.-- & $-.+\cdot+9$ & $-\Delta V \cdot$ & $1 / ז \Delta$ & $\cdot / K^{c}+c^{c}$ & $\cdot / T V T$ &.$/ 4 V$ & TA & امام زاده اسماعيل \\
\hline$-1 / 014$ & $-1 / I V t$ & -.1 .18 & -rTaV & $-1 / 8 r$ &.$- / R^{4}$ &.$- /$ FV $^{\mathrm{e}}$ & -.1 .99 & $-T_{A}$ & دشتى \\
\hline (- & -./TMI & $-\cdot / \cdot \cdot V$ & $-V Y \Delta$ & $r / M F$ & 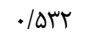 & . MAFF & .1 .91 & ED & خوبخله \\
\hline$-1 / T \Delta \Delta$ & - & $-.1 \cdot \mathrm{eV}^{\mathrm{V}}$ & - & $-\infty / \cdot \varphi$ & $-1 / \varepsilon \Delta \Delta$ & $-1 /$ K\&q & $-\cdot / \mathrm{AV}$ & $-\Delta$. & احمد آباد \\
\hline.$- / 194$ &.$- / 119$ & $-.1 . \cdot 9$ & $-V T \Lambda$ & T/T &.$/ 999$ &.$/ 991$ & $\cdot / 1 \cdot f^{2}$ & 91 & عباس آباد \\
\hline$-\cdot / \Delta \wedge \vee$ & $-\cdot / \wedge \& \Lambda$ & $-\cdot / \cdot r$. & $-9 \wedge 1$ & $-r / T$ & $-\cdot / 1 \mathrm{QA}$ & $-\cdot / \wedge \Delta$ & $-\cdot / \cdot r \Lambda$ & $-V$ & سده \\
\hline
\end{tabular}

بيشتر اين تحقيقات نشان مىدهد كه روند تغييرات بارش

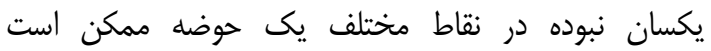

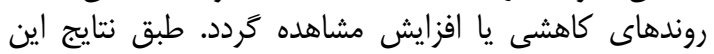

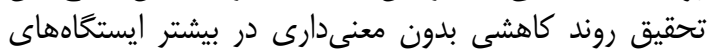

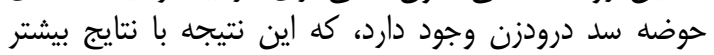

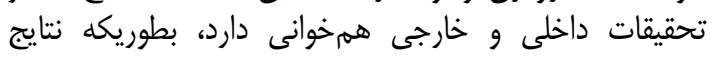

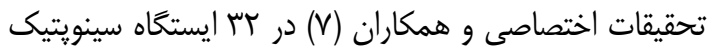

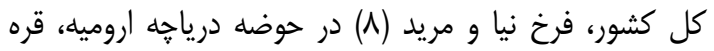

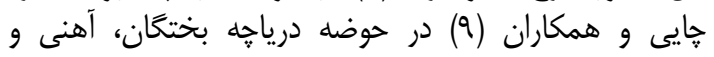

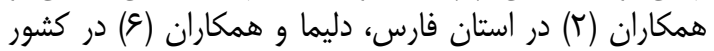

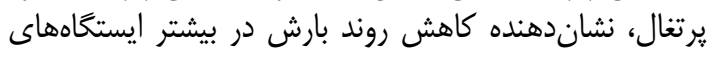

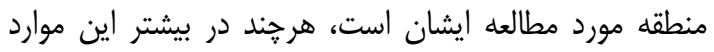
اين تغيير روند معنى دار نبوده است.

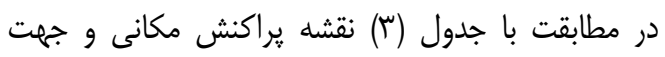

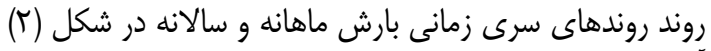

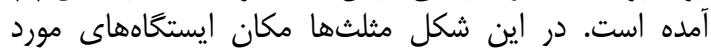

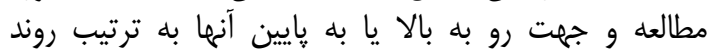

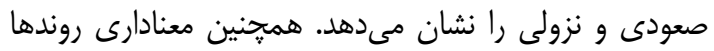

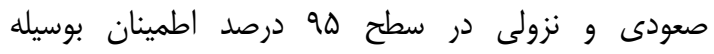

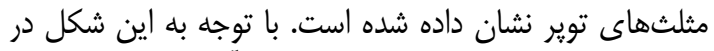

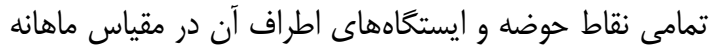

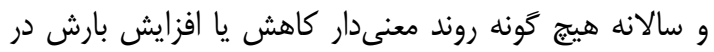

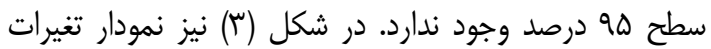

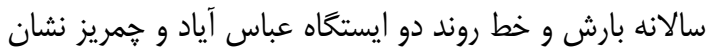
داده شده است.

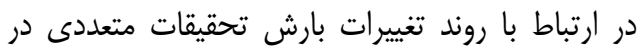

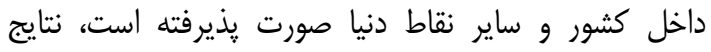




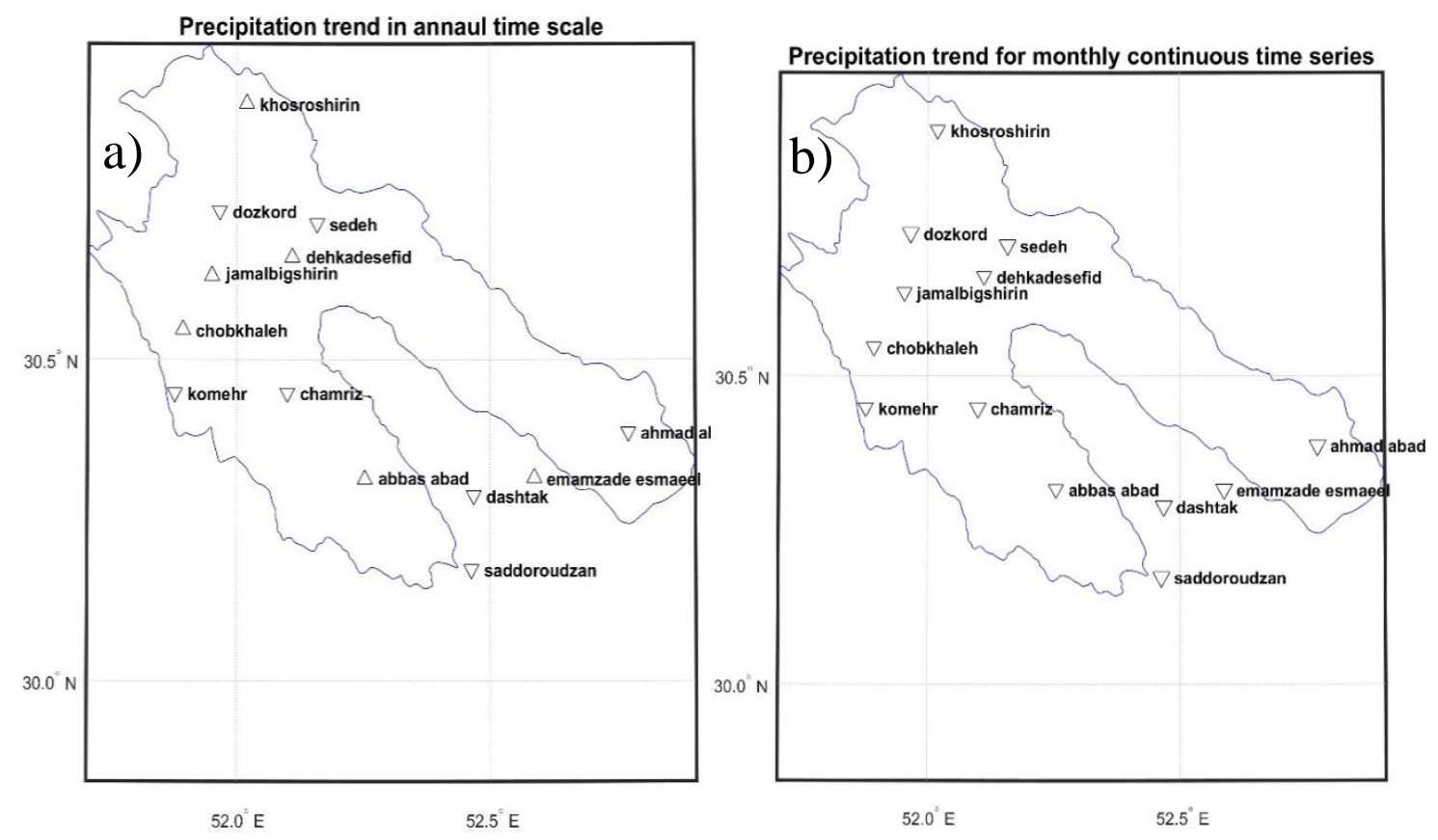

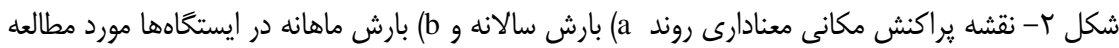

Figure 2. The spatial distribution map of trend significance of a) monthly rainfall and b) annual rainfall time series in the stations
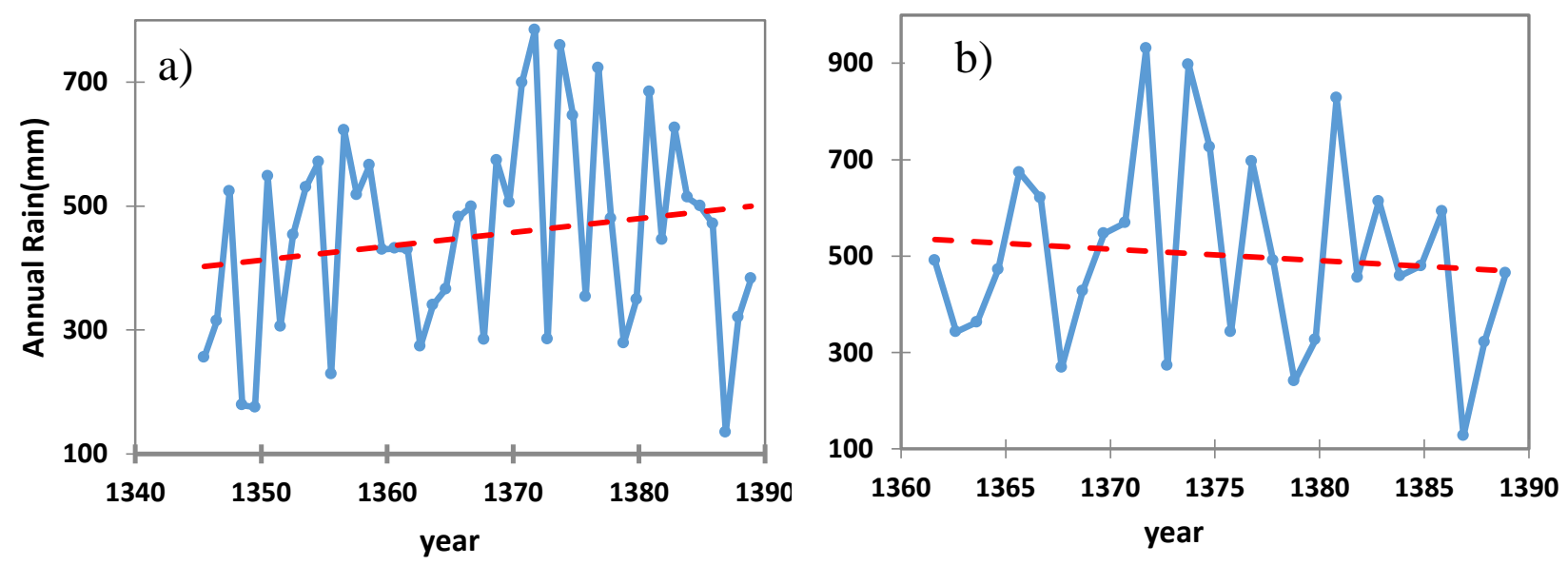

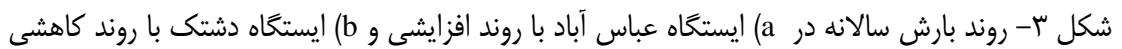

Figure 3. Annual rainfall trend in a) Abbas Abad station with an upward trend and، b) Dshtak station with a downward trend

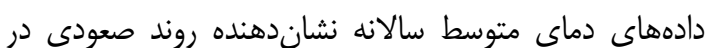

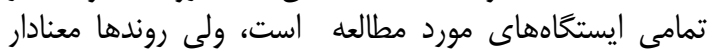

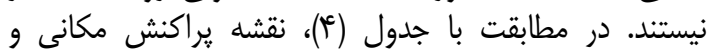

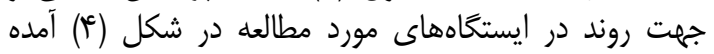

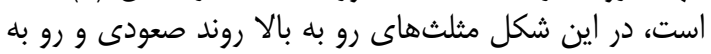

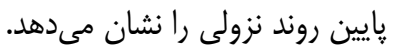

آزمون روند دادههاى دما

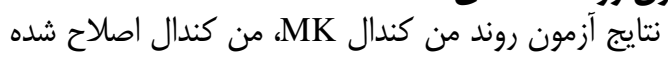

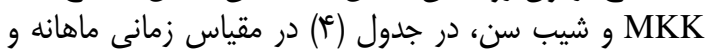

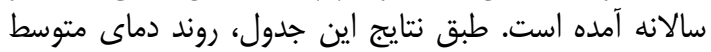

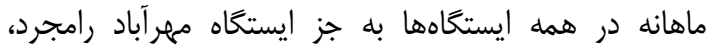

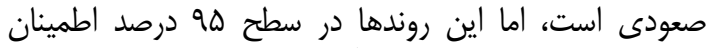

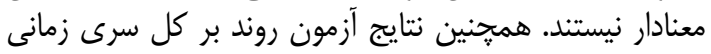


14. واكاوى تغييرات بلند مدت دما و بارش با هند روش نايارامترى شناسايى روند در حوضه سد درودزن .

كمهر T2 در روش MMK در سطح 99 درصد اطمينان معنىدار است. در مطابقت با نتايج جدول عأ، شكل ه ه نمودار

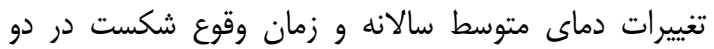

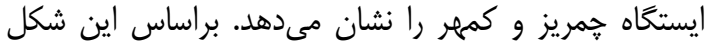

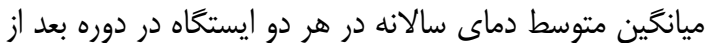

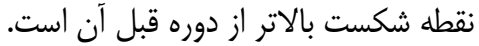

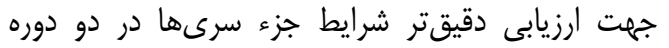

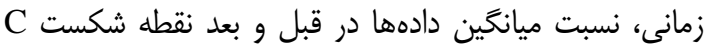

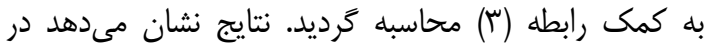

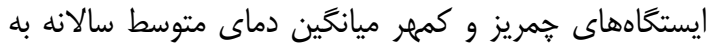

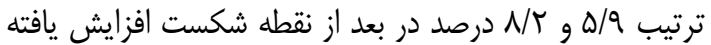

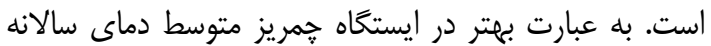

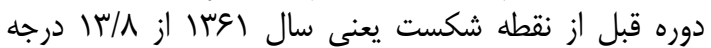

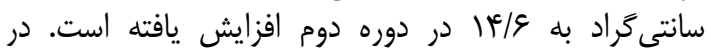

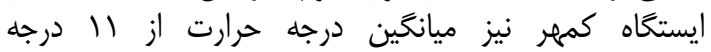

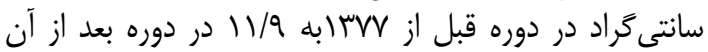
افزايش يافته است.
نتايج نشان از افزايش روند دما در سطح حوضه دارد،

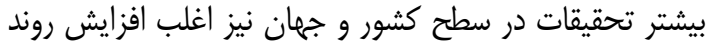

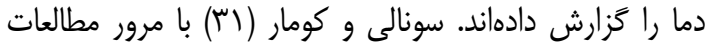

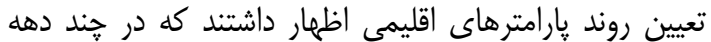
اخير افزايش دمايى رخ داده است و اغلب ائ اين تغيير بعدا ازئ سال

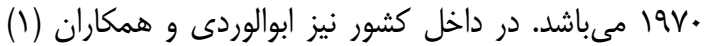

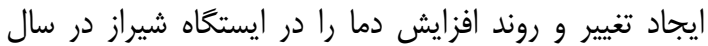

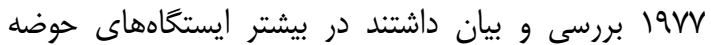

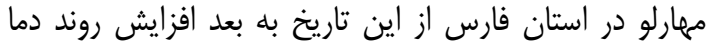

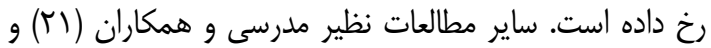

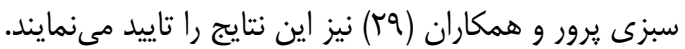

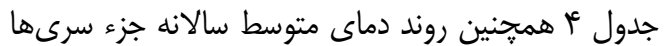

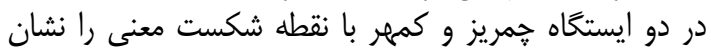
ميدهد. نتايج نشان داد، در هر دو ايستخاه روند سرى زمان زمانى

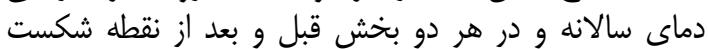

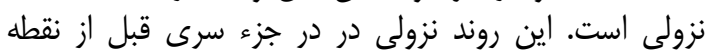

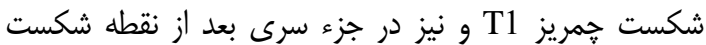

جدول f- نتايج آزمون روند دماى متوسط ماهانه و سالانه و همجنين روند دماى متوسط سالانه جزء سرىها در ايستخامهاى با نقطه شكست معنى دار

Table 4. Results of trend analysis of monthly and annual mean temperature، as well as the annual mean temperature trend of the series at the stations with a significant change point

\begin{tabular}{|c|c|c|c|c|c|c|c|c|c|c|}
\hline \multicolumn{5}{|c|}{ متوسط دماى ماهانه } & \multicolumn{5}{|c|}{ متوسط دماى سالانه } & \multirow[b]{2}{*}{ ايستخاه } \\
\hline Sen Slope & MMK & MK & $\begin{array}{c}\text { Kendall's } \\
\text { tau }\end{array}$ & S S S S S & Sen Slope & MMK & MK & $\begin{array}{c}\text { Kendall's } \\
\text { tau }\end{array}$ & آماره S & \\
\hline $.1 \cdots 1$ & $1 / F^{e V}$ & .1991 & $.1 \cdot 19$ & rVted & $.1 \cdot 14$ & $1 / .49$ & $1 / \cdot F^{c}$ &.$/ 11$ & 99 & جمريز \\
\hline سr...|•- & (r/ - - &.$- / 1 Y \varepsilon$ & $-\cdot / \cdot+f$ & $-\Delta \mid \Lambda$ & $.1 . .9$ & س & $\cdot / 9 t^{4}$ & .1 .91 & 91 & رمهر آباد \\
\hline \multirow[t]{4}{*}{$.1 \cdot+1$} & $1 / T \Lambda$ & $\cdot / \Delta \Delta 9$ & $.1 \cdot 19$ & rran & $.1 \cdot 11$ & $1 / \cdot 9$ & $1 / .9$ &.$/ 119$ & $1 \cdot 0$ & سده \\
\hline & & & & & $-\cdot / \cdot r$ & $-1 / M$ & $-1 / \wedge \mathrm{V}$ & $-\cdot / r \Delta Q$ & -91 & جمريز T2 \\
\hline & & & & &.$- / \cdot r$ & $-1 / \Delta V$ & $-1 / \Delta V$ & -.1191 & -91 & Tمهر \\
\hline & & & & & $-\cdot / 1 \cdot 0$ & 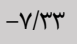 & $-1 / v 1$ &.$- / 411$ & שוt- & T2 كمر T2 \\
\hline
\end{tabular}




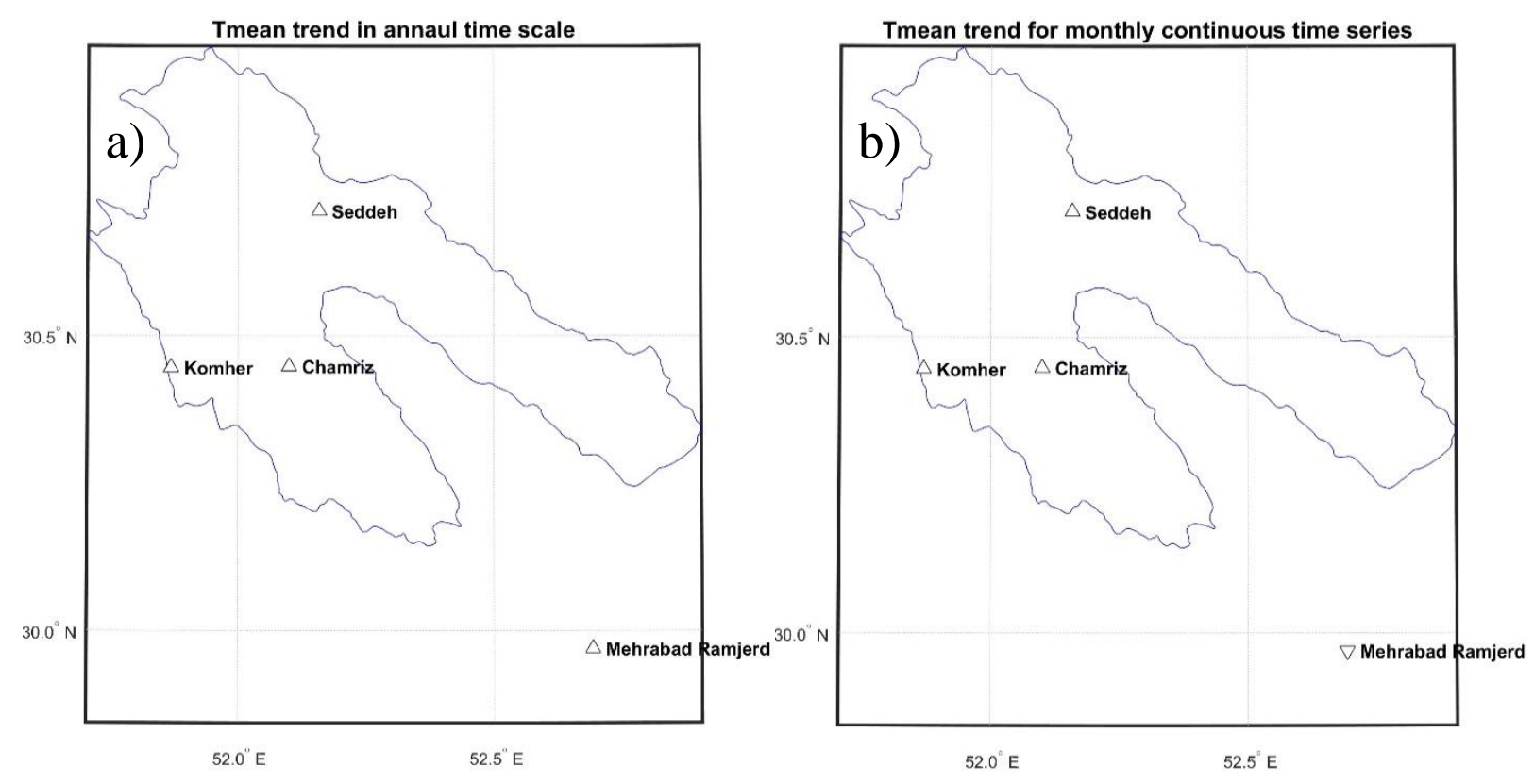

شكل ع- نقشه يراكنش مكانى معنادارى روند a (b) متوسط دماى سالانه و bتوسط دماى ماهانه در ايستخامها مورد مطالعه

Figure 4. The spatial distribution map of trend significance of a) monthly temperature and b) annual temperature time series in the stations
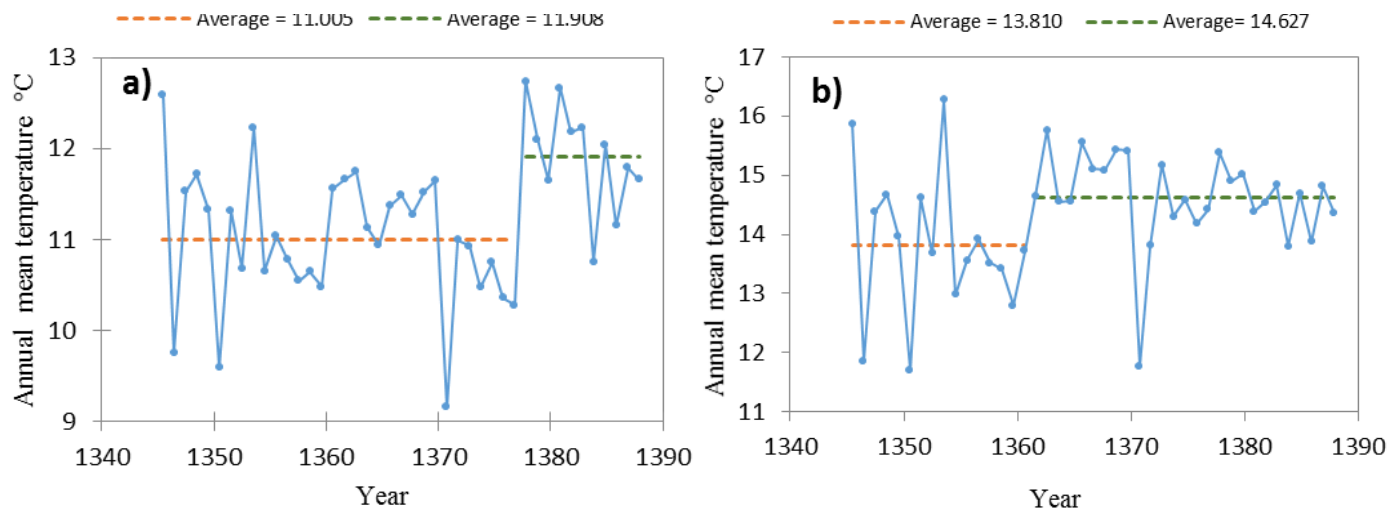

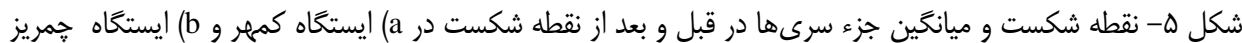

Figure 5. The change point and the average of the series before and after the change point in، a) Komer Station and، b) Chamriz Station

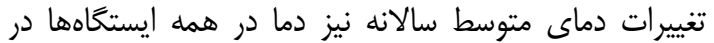

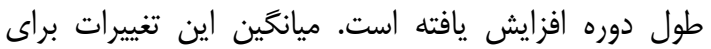

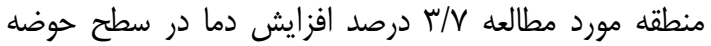

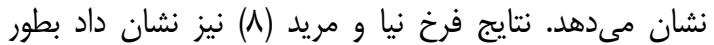

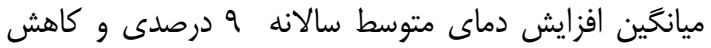

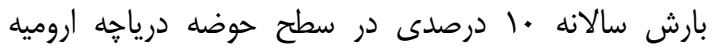

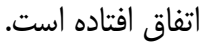

درصد تغييرات بارش و دما نسبت به ميانغين PC

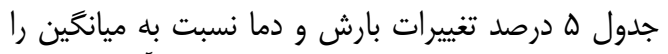

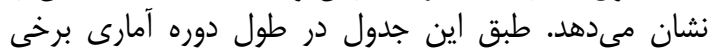

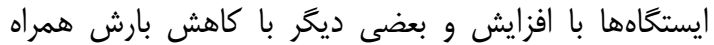

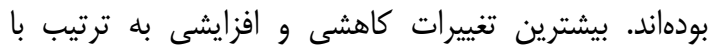

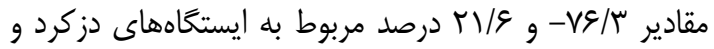

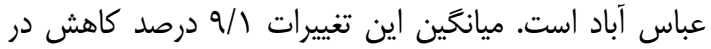

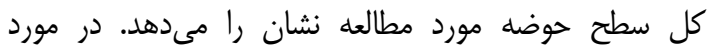


جدول ه- نتايج بررسى درصد تغييرات ڤارامترهاى بارش و دما نسبت به ميانخين (PC) Table 5. The percentage of the change in rainfall and temperature parameters compared to the mean of the time series

\begin{tabular}{|c|c|c|c|c|c|c|c|c|c|c|c|c|c|c|c|}
\hline ميانكين & جمريز & سده & عباس & آحمد & קֶوبخله & دشتك & سفيد & دزكرد & اسماعيل امزاده & شيرين & شيرين & كمهر & درودزن & ايستگًاه & \multirow[t]{2}{*}{ بارش } \\
\hline $9 / 1$ & $-r / \Delta$ & $-1 \cdot / \mathrm{V}$ & 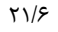 & r/ו" & $1 \cdot / \Lambda$ & -9 & $\Delta / \Delta$ & $-V \varepsilon / \mu$ & $1 . / 1$ & . & $8 / \Lambda$ & $-19 / \pi$ & $-r \mu / 1$ & PC & \\
\hline$r / v$ & & & & & & & & & & $r / V$ & $1 / \mathrm{V}$ & $\Delta / \Gamma$ & $r / r$ & PC & دما \\
\hline
\end{tabular}

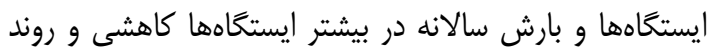

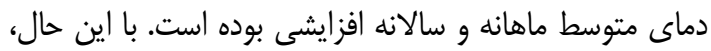

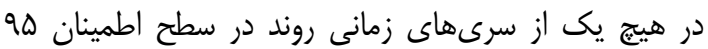

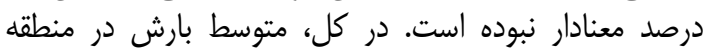

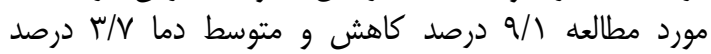

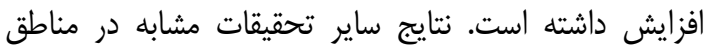

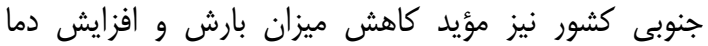

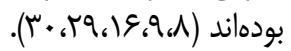

بررسى روند سرى زمانى متغيرهاى هواشناسى مىتواند

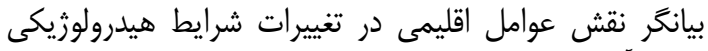

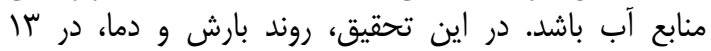

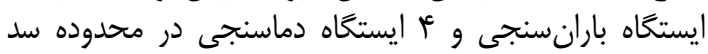

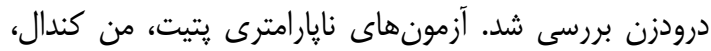

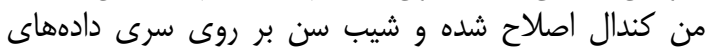

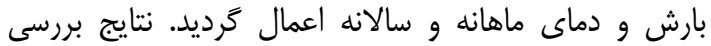

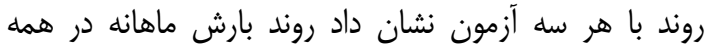

منابع

1. Abolverdi, J., G. Ferdosifar, D. Khalili, A.A. Kamgar-Haghighi and M.A. Haghighi. 2014. Recent trends in regional air temperature and precipitation and links to global climate change in the Maharlo watershed, Southwestern Iran. Meteorology and Atmospheric Physics, 126(3-4): 177-192.

2. Ahani, H., M. Kherad, M.R. Kousari, M. Rezaeian-Zadeh, M.A. Karampour, F. Ejraee and S. Kamali. 2012. An investigation of trends in precipitation volume for the last three decades in different regions of Fars province, Iran. Theoretical and Applied Climatology, 109(3): 361-382.

3. Ansari, M., G.R. Noori and S. Fotohi. 2017. Investigation of Temperature Precipitation and Flow Trend Using Nonparametric Mankendall (Case Study: Kaju River in Sistan and Baluchestan). journal of Watershed Management Research, 7(14): 152-158 (In Persian).

4. Dadashi Roudbari, A., G. Fallah Ghalheri, M. Karami and M. Baaghide. 2016. Analysis of Precipitation Variations of Haraz Watershed Using by Statistical Methods and Spectrum Analysis Technique. Scientific Journal Management System, 2(7): 59-86 (In Persian).

5. Darand, M. 2014. Analysis of variations in extreme temperature and precipitation in Uremia indices as the signs of climate change. Jornal of Water and Soil Conservation, 21(2): 1-29 (In Persian).

6. De Lima, M., S. Carvalho, J. De Lima and M. Coelho. 2010. Trends in precipitation: analysis of long annual and monthly time series from mainland Portugal. Advances in Geosciences, 25: 155-160.

7. Ekhtesasi, M.R., F. Jahanbakhshi and M.R. Kousari. 2015. Evaluating the Trend of Precipitation in 32 Synoptic Stations in Iran with Nonparametric Method and Moving Summation of Data for the Period of 1970 to 2005 with Ranks of 1 to 48 Months.Technical Note. Iran-Water Resources Research, 11(2): 151-156 (In Persian).

8. Farokhnia, A. and S. Morid. 2014. Assessment of the effects of temperature and precipitation variations on the trend of river flows in Urmia Lake watershed. Journal of Water and Wastewater, 25(3): 86-97 (In Persian).

9. Gharechaei, H., A. Moghaddam Nia, A. Malekian and A. Ahmadi. 2016. Separation of the effects of climate variability and human activities on runoff of Bakhtegan Basin. Iranian Journal of Eco hydrology, 2(4): 445-454 (In Persian).

10. Ghodoosi, M., S. Morid and M. Delavar. 2013. Comparison of detrending methods for the temperature and precipitations time series. Journa of Agricultural Meteorology, 1(2): $32-45$ (In Persian)

11. Hajam, S., Y. Khoush Khou and R. Shams Aldin Vandi. 2008. Annual and Seasonal Precipitation Trend Analysis of Some Selective Meteorological Stations In Central Region of Iran Using NonPoarametric Methods. Geography and Development, 40(64): 157- 168 (In Persian).

12. Hamed, K.H. and A.R. Rao. 1998. A modified Mann-Kendall trend test for autocorrelated data. Journal of Hydrology, 204(1-4): 182-196.

13. Jafarzadeh, M.S., H. Rouhani, A. Heshmatpoure and M. Kashani. 2016. Detecting Trend of Meteorological Series Across the Gorganrood Basin in the Last Three Decades. Journal of Watershed Management Research, 7(13): 230-240 (In Persian).

14. Khalili, K., M. Nazeri Tahrudi and F. Ahmadi. 2015. Application of PCI Index in the Annual and Seasonal Rainfall Pattern Investigation and Trend Analysis of Iran Duration the Recent Half Century. Iranian Journal of Irrigation and Drainage, 9(1): 195-208 (In Persian).

15. Khaliq, M.N., T.B.M.J. Ouarda, P. Gachon, L. Sushama and A. St-Hilaire. 2009. Identification of hydrological trends in the presence of serial and cross correlations: A review of selected methods and their application to annual flow regimes of Canadian rivers. Journal of Hydrology, 368: 117-130.

16. Kousari, M., M.T. Dastorani, Y. Niazi, E. Soheyli, M. Hayatzadeh and J. Chezgi. 2014. Trend Detection of Drought in Arid and Semi-Arid Regions of Iran Based on Implementation of Reconnaissance Drought Index (RDI) and Application of Non-Parametrical Statistical Method. Water Resour Manag, 28: 1857-1872. 
17. Kousari, M.R., H. Ahani and H. Hakimelahi. 2013. An investigation of near surface wind speed trends in arid and semiarid regions of Iran. Theoretical and Applied Climatology, 114(1): 153-168.

18. Kousari, M.R., M.A. Asadi Zarch, H. Ahani and H. Hakimelahi. 2013. A survey of temporal and spatial reference crop evapotranspiration trends in Iran from 1960 to 2005. Climatic Change, 120(1): $277-298$.

19. Kousari, M.R., M.R. Ekhtesasi and H. Malekinezhad. 2017. Investigation of long term drought trend in semi-arid, arid and hyper-arid regions of the world. Desert Management, 8(Autumn \& Winter,): 3653 (In Persian).

20. Marofi, S., B. khatar, M. Sadeghifar, N. Parsafar and A. Ildoromi. 2014. Drought Forecasting Using SARIMA Time Series Model and SPI Index for Central Parts of Hamedan Province. Journal of Water Research in Agriculture, 28(1): 213-225 (In Persian).

21. Modaresi, F., S. Araghinejad, K. Ebrahimi and M. Kholghi. 2010. Regional assessment of climate change using statistical tests: Case Study of Gorganroud-Gharehsou Basin. Journal of water and soil, 24(3): 476-489 (In Persian).

22. Mofidi, A., M. Hamidianpour, M. Salihgheh and B. Alijani. 2014. Determination of the Onset, Withdrawal and Duration of Sistan wind using a Change Point Approach. Geography and Environmental Hazard, 2(8): 87-112 (In Persian).

23. Morozova, A.L. and M.A. Valente. 2012. Homogenization of Portuguese long-term temperature data series: Lisbon, Coimbra and Porto, . Earth Syst. Sci. Data, 4: 187-213.

24. Nafarzadegan, A.R., M. Rezaeian Zadeh, M. Kherad, H. Ahani, A. Gharehkhani, M.A. Karampoor and M.R. Kousari. 2012. Drought area monitoring during the past three decades in Fars province, Iran. Quaternary International, 250: 27-36.

25. Nassaji Zavareh, M., A. Khorshiddoust, A. Rasouli and A. Slajegheh. 2014. Assessment of Discharge Trend of Kasilian Watershed. Iranian Journal of Watershed Management Science \& Engineering, 8(24): 1-8 (In Persian).

26. Pal, I. and A. Al-Tabbaa. 2011. Assessing seasonal precipitation trends in India using parametric and non-parametric statistical techniques. Theoretical and Applied Climatology, 103(1-2): 1-11.

27. Rahimi, L., A.A. Dehghani and K. Ghorbani. 2016. Comparison of Total flow, Base flow and WaterQuality Characteristics Trend in Arazkuseh Hydrometric Station. Journal Of Watershed Management Research, 7(13): 83-91(In Persian).

28. Ranjbar, A., D. Khalili, S. Zand Parsa and A.A. Kamgar-Haghighi. 2015. Regional Drought Monitoring Based on Infelow Into The Doroodzan Reservoir OIR In Fars Province. Journal of Irrigation Science and Engineering, 38(1): 79-96 (In Persian).

29. Sabziparvar, A.A., Z. Seif and F. Ghiyami. 2013. Analysis of Temperature changes Trend in Arid and Semi-arid Regions. Geography and Development, 11: 139-156 (In Persian).

30. Salarijazi, M., A.M. Akhond-Ali, A. Adib and A. Daneshkhah. 2012. Trend and change-point detection for the annual stream-flow series of the Karun River at the Ahvaz hydrometric station. African Journal of Agricultural Research, 7(32): 4540-4552.

31. Sonali, P. and D.N. Kumar. 2013. Review of trend detection methods and their application to detect temperature changes in India. Journal of Hydrology, 476: 212-227.

32. Torabi Poodeh, H. and S. Emamgholizadeh. 2015. Trend analysis of streamflow changing of north watershed of Dez River with TFPW-MK procedure. Journal of Water and Soil Conservation, 22(3): 39-55 (In Persian).

33. Yue, S. and C. Wang. 2004. The Mann-Kendall Test Modified by Effective Sample Size to Detect Trend in Serially Correlated Hydrological Series. Water Resources Management, 18: 201-218. 


\title{
Analysis of Trends in Temperature and Precipitation in Doroodzan Dam Basin using the Modified Mann-Kendall Test
}

\author{
Esmaeil Soheili ${ }^{1}$, Hussein Malekinezhad ${ }^{2}$ and Mohammad Reza Ekhtesasi ${ }^{3}$
}

1- PhD Graduated, College of Natural Resources and Desert Studies, Yazd University, Iran

2- Associate Professor, College of Natural Resources and Desert Studies, Yazd University, Iran (Corresponding Author: hmalekinezhad@yazd.ac.ir)

3- Professor, College of Natural Resources and Desert Studies, Yazd University, Iran

Received: August 4, 2017

Accepted: September 26, 2017

\begin{abstract}
Doroodzan Dam basin is one of the strategic agricultural areas in Fars province. Changes in time series of climatic parameters, especially temperature and precipitation parameters, can have a significant impact on the growth cycle of agricultural products, the status of water resources and the economy of the populations in the area. In the present study, rainfall and temperature trends were investigated in 13 rainfall stations and 4 thermometric stations. Initially, the change point pettitt test was used to assess the homogeneity and change point in the time series. Then, trends in the rainfall, average monthly and annual temperature time series were investigated using Mann-Kendall (MK), modified Mann-Kendall (MMK) and the sen's slope methods. The results of the pettitt test showed that there is no significant change point in the monthly and annual rainfall and monthly temperature time series, only in the annual temperature of two stations, there is a significant change point at the $95 \%$ confidence level. The results of the trend analysis with all three abovementioned methods showed that the monthly precipitation in all stations and annual precipitation in most stations have a decreasing trend and the average monthly and annual temperature have an increasing trend; however, in none of the time series, the trend was significant in the confidence level of $95 \%$. Based on the results, in the whole area, the mean annual temperature increased by 3.7 percent and precipitation decreased by 9.1 percent compared to the mean.
\end{abstract}

Keywords: Change Point, Fars Province, Sen's Slope, Trend, Modified Mann-Kendall 